\title{
FACTORIAL DESIGN AS THE METHOD IN THE OPTIMIZATION OF TIMOLOL MALEATE- LOADED NANOPARTICLE PREPARED BY IONIC GELATION TECHNIQUE
}

\author{
WILDAN KHAIRI MUHTADI ${ }^{1}$, LARAS NOVITASARI ${ }^{1}$, RONNY MARTIEN $^{1 *}$, RETNO DANARTI $^{2}$
}

1Departement of Pharmaceutics, Faculty of Pharmacy, Universitas Gadjah Mada, Sekip Utara, D. I. Yogyakarta 55281, Indonesia, ${ }^{2}$ Department of Dermatology and Venereology, Faculty of Medicine, Public Health and Nursing, Universitas Gadjah Mada, Farmako Sekip Utara, D. I. Yogyakarta 55281, Indonesia

Email: ronnymartien@ugm.ac.id

Received: 04 Jun 2019, Revised and Accepted: 04 Jul 2019

\section{ABSTRACT}

Objective: This study aims to optimize the timolol maleate (TM) nanoparticle prepared by ionic gelation method using the factors of pectin (PC) calcium chloride (CC), and chitosan (CS) concentrations with the responses of entrapment efficiency, particle size, and polydispersity index using $2^{3}$ factorial design.

Methods: TM nanoparticle suspensions were obtained by mixing of PC $(0,4-0,6 \%(\mathrm{w} / \mathrm{v})), \mathrm{CC}(0,2-0,4 \%(\mathrm{w} / \mathrm{v}))$, and CS $(0,01-0,02 \%(\mathrm{w} / \mathrm{v}))$ with TM concentration of $0,02 \% \mathrm{w} / \mathrm{v}$. Each mixture was then tested for entrapment efficiency, particle size, and polydispersity index. The test results were analyzed with $2^{3}$ factorial design using Design-Expert software in order to determine the optimum formula.

Results: The optimization study showed that all of the factors influenced the responses significantly $(\mathrm{p}<0.05)$ based on the analysis of variance (ANOVA) of the suggested models. The R2value and the adequate precision value of the three models were more than 0.7 and 4 , respectively. The difference between Adjusted R-Squared and Predicted R-Squared value were less than 0.200 . The optimum condition of TM nanoparticle was suggested at the desirability value of 0.839 with the concentration of PC, CC, and CS of $0,4 \%(\mathrm{w} / \mathrm{v}), 0,2 \%(\mathrm{w} / \mathrm{v})$, and $0,01 \%(\mathrm{w} / \mathrm{v})$, respectively. The entrapment efficiency, particle size, and polydispersity index of the optimum condition were $24.791 \pm 2.84 \%, 274.867 \pm 14.45 \mathrm{~nm}$, and $0.634 \pm 0.066$, respectively.

Conclusion: The $2^{3}$ factorial design has been proved as the suitable method to determine the optimum condition that yields the good results of the entrapment efficiency, particle size, and polydispersity index of the TM-loaded nanoparticle prepared by ionic gelation method.

Keywords: Nanoparticle, Ionic gelation, Timolol maleate, Pectin, Calcium chloride, Chitosan, Factorial design

(C) 2019 The Authors. Published by Innovare Academic Sciences Pvt Ltd. This is an open access article under the CC BY license (http://creativecommons.org/licenses/by/4.0/) DOI: http://dx.doi.org/10.22159/ijap.2019v11i5.34435

\section{INTRODUCTION}

Timolol maleate (TM) is a $\beta$-blocker agent which has a promising alternative in the treatment of infantile hemangioma (IH), a benign vascular tumor that frequently occurs in infants with the prevalence of approximately $4-10 \%$ in the first year of life $[1,2]$. Application of topical TM for IH treatment shows better efficacy and less potency of adverse effect. A recent study exhibited a significant decrease of IH surface area treated with topical timolol maleate compared with topical corticosteroid [1]. Nevertheless, topical use of TM is reported to reach systemic circulation, which can produce undesirable effects [3].

Polymeric nanoparticle can be utilized in order to provide an effective therapy of IH using TM with less potency to be absorbed through the systemic circulation. A polymeric nanoparticle is one of the drug carriers that can be used in the formulation of a topical dosage form. It possesses several abilities such as protecting the drug trapped inside the nano-sized particle from degradation or denaturation and decreasing the potency of systemic absorption by providing sustained release of drug from the dosage form [4]. The nanoparticle can be made by the method of ionic gelation, which is a method that utilized the electrostatic interaction between cationic and anionic polymer that spontaneously from nano-sized particles. This advantageous method only requires simple stirring without the use of organic solvents that mostly possess toxic properties [5-7].

The ionic gelation system can be achieved in the event of ionic interaction between the oppositely charged polymers and crosslinking agents that subsequently able to encapsulate the drug molecules. Pectin (PC) is an anionic polymer extracted from plant cell walls. The combination of PC with chitosan (CS) as the cationic polymer and calcium chloride (CC) as the cross-linker ion yields the nanoparticulate system with the nano-sized particles and drug encapsulated inside the particles. The combination has also prolonged the release of drug from nanoparticle so that the frequency of drug administration can be reduced [8].
The concentration of polymers and cross-linking agents used in the ionic gelation greatly affects the nanoparticle formed. An optimum value of several parameters such as entrapment efficiency, particle size, and polydispersity index can be achieved by the appropriate concentration of PC, CC, and CS. The use of factorial design as one of the methods of nanoparticle formula optimization can be conducted in order to determine the factors affecting the experiment results and to observe the level of factors that generate the desirable responses [9].

This study aims to observe the effect of PC, CC, and CS concentrations on the entrapment efficiency, particle size, and polydispersity index of the timolol maleate-loaded nanoparticle manufactured with ionic gelation method. Formula optimization is conducted with $2^{3}$ factorial design using three replicates to analyze the effects of the three selected factors.

\section{MATERIALS AND METHODS}

\section{Materials}

Timolol maleate (TM) was purchased from Octagon Chemicals Limited (China), pectin (PC) was purchased from Sigma Aldrich (Darmstadt, Germany), calcium chloride (CC) was purchased from Merck (Germany), chitosan (CS) was purchased from local company Chimultiguna (Cirebon, Indonesia), glacial acetic acid, hydrochloric acid, and sodium hydroxide were purchased from Merck (New Jersey, USA).

\section{Instrumentation and software}

The entrapment efficiency of TM in nanoparticle was analyzed using UV-Vis spectrophotometer (Thermo Scientific Genesys 10S UV). The particle size, polydispersity index, and zeta potential of nanoparticle were analyzed by the method of dynamic light scattering (DLS) using Zetasizer Nano ZS (Malvern, UK). The optimization study was analyzed using Design-Expert software (Stat-Ease Inc., Minneapolis, 
MN, USA). The verification study of optimum nanoparticle formula was analyzed statistically using $\mathrm{R}$ free software.

\section{Formula optimization using a factorial design}

Formula optimization was conducted with $2^{3}$ factorial design using Design-Expert software. Concentration of PC $\left(\mathrm{X}_{1}\right) \mathrm{CC}\left(\mathrm{X}_{2}\right)$, and CS $\left(\mathrm{X}_{3}\right)$ were used as factors, whereas entrapment efficiency $\left(\mathrm{Y}_{1}\right)$, particle size $\left(\mathrm{Y}_{2}\right)$, and polydispersity index $\left(\mathrm{Y}_{3}\right)$ were used as responses.

\section{Prediction and verification of optimum nanoparticle formula}

The prediction of the optimal condition of nanoparticle preparation was conducted by determining the priority value of each response $(\mathrm{Y})$ in Design-Expert software. The verification of optimal condition was conducted by comparing the three replicates of experiment data with the predicted value provided by the software. Data were analyzed with one-sample t-test using R free software at $95 \%$ of confidence interval ( $>0.05$ ) and using Design-Expert software by observing the $95 \%$ confidence interval (CI) and 95\% prediction interval (PI).

\section{Preparation of TM-loaded PC-CS nanoparticle}

PC solutions $(0,4-0,6 \%(\mathrm{w} / \mathrm{v}))$ and CC solutions $(0,2-0,4 \%(\mathrm{w} / \mathrm{v}))$ were obtained by dissolving certain amounts of PC and CC separately in demineralized water for $2 \mathrm{~h}$ with constant stirring. CS solutions $(0,01-0,02 \%(\mathrm{w} / \mathrm{v}))$ were obtained by dissolving certain amounts of CS with $1 \%$ of acetic acid $(\mathrm{v} / \mathrm{v})$ solution in overnight constant stirring. TM solution $(0,02 \%(\mathrm{w} / \mathrm{v}))$ was obtained by dissolving certain amounts of TM in demineralized water with constant stirring. Furthermore, $2 \mathrm{ml}$ of PC solution was added with $0,1 \mathrm{ml}$ of TM solution with constant stirring for an hour. 1,9 $\mathrm{ml}$ of CC solution was then added to the mixture solution of PC and TM and stirred for $30 \mathrm{~min}$ to complete the pre-gelation process. Finally, $1 \mathrm{ml}$ of CS was added to the pre-gel solution and stirred for $30 \mathrm{~min} \mathrm{[10].}$

\section{Entrapment efficiency}

Nanoparticle sample was centrifuged with a speed of $15000 \mathrm{rpm}$ for $30 \mathrm{~min}$ at $4{ }^{\circ} \mathrm{C}$ to separate the unentrapped drug with the nanoparticle precipitate. The supernatant was then diluted with $\mathrm{HCl}$ $0,1 \mathrm{M}$ and analyzed for TM content using UV-Vis spectrophotometer at $296 \mathrm{~nm}$. HCl 0,1 M was used as the blank. The test was conducted in three replicates for each sample. The entrapment efficiency (EE) value was calculated using following equation:

$$
\mathrm{EE}(\%)=\frac{\text { Total amount of TM }- \text { free } \mathrm{TM} \text { in the supernatant }}{\text { Total amount of TM }} \times 100
$$

Table 1: The condition of each experiment in the factorial design and their responses $(n=24)$

\begin{tabular}{|c|c|c|c|c|c|c|c|}
\hline \multirow[t]{2}{*}{ Run } & \multirow[t]{2}{*}{ Std } & \multicolumn{3}{|l|}{ Factor } & \multicolumn{3}{|l|}{ Response } \\
\hline & & $\begin{array}{l}\mathrm{X}_{1} \text { : Concentration } \\
\text { of PC }(\%)\end{array}$ & $\begin{array}{l}\mathrm{X}_{2} \text { : Concentration } \\
\text { of CC }(\%)\end{array}$ & $\begin{array}{l}\mathrm{X}_{3} \text { : Concentration } \\
\text { of } \operatorname{CS}(\%)\end{array}$ & $\begin{array}{l}Y_{1} \text { : Entrapment } \\
\text { efficiency }(\%)\end{array}$ & $\begin{array}{l}Y_{2}: \text { Particle } \\
\text { size }(\mathrm{nm})\end{array}$ & $\begin{array}{l}Y_{3} \text { : Polydispersity } \\
\text { index }\end{array}$ \\
\hline 1 & 17 & 0,6 & 0,2 & 0,02 & 18,097 & 337,1 & 0,652 \\
\hline 2 & 22 & 0,6 & 0,4 & 0,02 & 15,757 & 345,1 & 0,632 \\
\hline 3 & 8 & 0,4 & 0,4 & 0,01 & 13,417 & 495,3 & 0,653 \\
\hline 4 & 21 & 0,4 & 0,4 & 0,02 & 13,417 & 177,8 & 0,489 \\
\hline 5 & 12 & 0,6 & 0,4 & 0,01 & 19,267 & 262,1 & 0,54 \\
\hline 6 & 4 & 0,6 & 0,2 & 0,01 & 21,607 & 369,5 & 0,622 \\
\hline 7 & 16 & 0,6 & 0,2 & 0,02 & 13,417 & 348,7 & 0,645 \\
\hline 8 & 15 & 0,4 & 0,2 & 0,02 & 23,947 & 383,6 & 0,579 \\
\hline 9 & 1 & 0,4 & 0,2 & 0,01 & 25,11 & 278,9 & 0,669 \\
\hline 10 & 19 & 0,4 & 0,4 & 0,02 & 15,757 & 292 & 0,556 \\
\hline 11 & 6 & 0,6 & 0,2 & 0,01 & 20,437 & 431,8 & 0,657 \\
\hline 12 & 2 & 0,4 & 0,2 & 0,01 & 29,797 & 277,2 & 0,698 \\
\hline 13 & 10 & 0,6 & 0,4 & 0,01 & 18,097 & 213,5 & 0,561 \\
\hline 14 & 5 & 0,6 & 0,2 & 0,01 & 26,287 & 357,6 & 0,639 \\
\hline 15 & 9 & 0,4 & 0,4 & 0,01 & 20,437 & 332,4 & 0,625 \\
\hline 16 & 20 & 0,4 & 0,4 & 0,02 & 18,097 & 212,8 & 0,526 \\
\hline 17 & 23 & 0,6 & 0,4 & 0,02 & 18,097 & 253,8 & 0,636 \\
\hline 18 & 24 & 0,6 & 0,4 & 0,02 & 13,417 & 325.9 & 0,484 \\
\hline 19 & 14 & 0,4 & 0,2 & 0,02 & 20,437 & 474,5 & 0,617 \\
\hline 20 & 7 & 0,4 & 0,4 & 0,01 & 15,757 & 334,3 & 0,687 \\
\hline 21 & 3 & 0,4 & 0,2 & 0,01 & 27,457 & 247,3 & 0,687 \\
\hline 22 & 11 & 0,6 & 0,4 & 0,01 & 22,777 & 233,5 & 0,497 \\
\hline 23 & 13 & 0,4 & 0,2 & 0,02 & 20,437 & 438,4 & 0,519 \\
\hline 24 & 18 & 0,6 & 0,2 & 0,02 & 15,757 & 308,1 & 0,656 \\
\hline
\end{tabular}

\section{Particle size and polydispersity index}

The test was conducted using a particle size analyzer instrument of Zetasizer Nano ZS (Malvern, UK). A number of timolol maleate nanoparticle sample was put into the cuvette and analyzed in three replicates [11].

\section{RESULTS AND DISCUSSION}

\section{Optimization studies using a factorial design}

Factorial design is one of the methods commonly used in optimization study using the design of the experimental (DoE) approach. The method can be purposed to probe factors that influence the outcome of the experiment. Moreover, the levels of factors that generate a better response in the experiment can also be observed using factorial design [9]. Variables that can be controlled by the investigator can be used as factors in factorial design. In this study, the concentration of PC, CC, and CS were used as factors due to the fact that the process of polymeric nanoparticle preparation is influenced by the concentration of polymers and cross-linking agents [12-14]. The results of the optimization study that was conducted using factorial were presented as 24 experiment conditions (table 1).

Table 2: The regression equations of all responses used in the design of experimental

\begin{tabular}{ll}
\hline Response & Regressed equation \\
\hline Entrapment Efficiency $\left(\mathrm{Y}_{1}\right)$ & $\mathrm{Y}_{1}=64.199-43.854 \mathrm{X}_{1}-141.348 \mathrm{X}_{2}-447.975 \mathrm{X}_{3}+175.470 \mathrm{X}_{1} \mathrm{X}_{2}-1170.583 \mathrm{X}_{1} \mathrm{X}_{3}+1949.416 \mathrm{X}_{2} \mathrm{X}_{3}$ \\
Particle Size $\left(\mathrm{Y}_{2}\right)$ & $\mathrm{Y}_{2}=-2457.067+5292 \mathrm{X}_{1}+9423.833 \mathrm{X}_{2}+182940 \mathrm{X}_{3}-18013.333 \mathrm{X}_{1} \mathrm{X}_{2}-335217 \mathrm{X}_{1} \mathrm{X}_{3}-613150 \mathrm{X}_{2} \mathrm{X}_{3}+1.127670 \mathrm{X}_{1} \mathrm{X}_{2} \mathrm{X}_{3}$ \\
Polydispersity Index $\left(\mathrm{Y}_{3}\right)$ & $\mathrm{Y}_{3}=1.205-0.826 \mathrm{X}_{1}+0.206 \mathrm{X}_{2}-44.550 \mathrm{X}_{3}-1.200 \mathrm{X}_{1} \mathrm{X}_{2}+76.833 \mathrm{X}_{1} \mathrm{X}_{3}+5.333 \mathrm{X}_{2} \mathrm{X}_{3}$ \\
\hline
\end{tabular}


The analysis of variance (ANOVA) of the suggested models generated by Design-Expert software indicated that three factors influenced the responses used that showed by a significant model $(p<0.05)$ of the three responses. The equation model of the three responses $\left(\mathrm{Y}_{1}, \mathrm{Y}_{2}\right.$, and $\left.\mathrm{Y}_{3}\right)$ was statistically able to predict the optimum condition of nanoparticle preparation. The regression equation (table 2) showed the contribution of each factor on increase and decrease of the evaluated responses marked by positive and negative signs, respectively.

Table 3: The results of the acceptance criteria of statistical parameters of the experimental design

\begin{tabular}{|c|c|c|c|c|c|c|}
\hline Response & SD & $\mathrm{CV}$ & $\mathbf{R}^{2}$ & Adjusted $\mathrm{R}^{2}$ & Predicted $\mathrm{R}^{2}$ & Adequate Precision \\
\hline$Y_{1}$ : Entrapment Efficiency & 2.55 & 19.46 & 0.7774 & 0.6989 & 0.5564 & 8.489 \\
\hline $\mathrm{Y}_{2}$ : Particle Size & 49.39 & 15.33 & 0.7546 & 0.6472 & 0.4479 & 7.176 \\
\hline $\mathrm{Y}_{3}$ : Polydispersity Index & 0.041 & 6.77 & 0.7251 & 0.6281 & 0.4522 & 7.273 \\
\hline
\end{tabular}

Based on the factorial method parameter on DoE (table 3), $\mathrm{R}^{2}$ measure the effect of factor to the response in the equation, the higher $\mathrm{R}^{2}$ (more than 0.7) more preferable $\left(\mathrm{Y}_{1}=0.7774 ; \mathrm{Y}_{2}=0.7546\right.$; $\mathrm{Y}_{3}=0.7251$ ). The difference between Adjusted R-Squared and Predicted R-Squared value must be less than $0.200 \quad\left(\mathrm{Y}_{1}=0.1425\right.$; $\left.Y_{2}=0.1993 ; Y_{3}=0.1759\right)$ and a good correlation between the actual value and prediction value of the three responses were presented by predicted vs actual plots (fig. 1A, 1B, 1C). Adequate Precision showed the signal to noise ratio and must be more than $4\left(\mathrm{Y}_{1}=8.489\right.$; $\mathrm{Y}_{2}=7.176 ; \mathrm{Y}_{3}=7.273$ ); thus all response indicates the adequate equation to describe the relationship between factors to responses [15-17].

\section{Entrapment efficiency}

The entrapment efficiency $\left(\mathrm{Y}_{1}\right)$ of the 24 experiments was varied from $13.417 \%$ to $29.797 \%$ (table 1 ). Based on the ANOVA analysis, the model of entrapment efficiency response $\left(\mathrm{Y}_{1}\right)$ was significant with the $p$-value of $<0.0001(\mathrm{p}<0.05)$. The factor of CC concentration $\left(\mathrm{X}_{2}\right)$ and interaction between factors of concentration of PC and concentration of $\mathrm{CC}\left(\mathrm{X}_{1} \mathrm{X}_{2}\right)$ possessed a significant effect with the $\mathrm{p}$ value of 0.0003 and 0.0036 , respectively.

The factor of $X_{2}$ possessed a negative effect, whilst the interaction of $\mathrm{X}_{1} \mathrm{X}_{2}$ possessed a positive effect on the response of entrapment efficiency. The negative effect of CC concentration indicates that the decrease of entrapment efficiency with increasing the concentration of CC (fig. 2A). The excess $\mathrm{Ca}^{2+}$ ion resulted in a high concentration of CC decrease the strength of gel surface in the pregelation process. There is a possibility that the high concentration of CC $(0,4 \%)$ used in this study generates saturation of calcium ions in the nanoparticle preparation lead to a decrease of entrapment efficiency [18].

The entrapment efficiency is also affected by the interaction between the concentration of PC and CC. It can be seen in the table 1 that in the most of experiments with the low concentration of CC $(0.2 \%(w / v))$, the entrapment efficiency values were lower when the high concentration of PC $(0.6 \%(\mathrm{w} / \mathrm{v}))$ is used than the low concentration of PC $(0.4 \%(\mathrm{w} / \mathrm{v}))$. The decrease of entrapment efficiency can be occurred due to the increase of the solution viscosity generated by a high concentration of PC. The higher solution viscosity subsequently causes an inadequate interaction between the PC and the cross-linking agent [19].

\section{Particle size}

The results of experiments showed that the response of particle size $\left(\mathrm{Y}_{2}\right)$ of the 24 runs was varied between $177.8 \mathrm{~nm}$ and $495.3 \mathrm{~nm}$. The ANOVA analysis indicated that the suggested model was significant with the $\mathrm{p}$-value of $0.0006(\mathrm{p}<0.05)$. All of the factors $\left(\mathrm{X}_{1}, \mathrm{X}_{2}, \mathrm{X}_{3}\right)$ and interaction of factors $\left(\mathrm{X}_{1} \mathrm{X}_{2}, \mathrm{X}_{1} \mathrm{X}_{3}, \mathrm{X}_{2} \mathrm{X}_{3}\right)$ were significant with the $\mathrm{p}$ values of $<0.0001(\mathrm{p}<0.05)$.

Based on the regression equation of particle size response, the factors of $\mathrm{PC}\left(\mathrm{X}_{1}\right)$ and $\mathrm{CC}\left(\mathrm{X}_{2}\right)$ concentrations showed positive effects, which indicate that the higher concentration of $\mathrm{PC}$ and $\mathrm{CC}$, the bigger particle size will be yielded. The effects were also illustrated by the 3D surface of particle size (fig. 2B). This finding is in accordance with the previous study describing that the small particles are formed when the low concentration of PC and divalent cation [20]. The concentration of $\mathrm{CS}\left(\mathrm{X}_{3}\right)$ was also indicated a positive effect on the particle size of TM nanoparticle. The higher chitosan concentration increases the viscosity of nanoparticle preparation and subsequently slower the gelation process which yields the higher particle size [21] The interaction between the factor of $X_{1}$ and $X_{3}$ showed negative effect indicates that small and stable colloid particles will be formed in the adequate interaction between PC's carboxylate groups and oppositely charged amino groups of CS [22].

\section{Polydispersity index}

The results of 24 runs showed that the values of polydispersity index $\left(\mathrm{Y}_{3}\right)$ were between 0.484 and 0.698 . The ANOVA analysis indicated that the suggested model was significant with the p-value of 0.0005 $(p<0.05)$. The factors of PC concentration $\left(X_{1}\right), C S$ concentration $\left(X_{3}\right)$, and interaction between of $\mathrm{PC}$ and $\mathrm{CS}\left(\mathrm{X}_{1} \mathrm{X}_{3}\right)$ were significant with the $p$-values of $0.0366,0.0003$, and 0.0003 , respectively $(p<0.05)$. Based on the produced regression equation (table 2), the negative effect of $\mathrm{PC}$ concentration $\left(\mathrm{X}_{1}\right)$ and $\mathrm{CS}$ concentration $\left(\mathrm{X}_{3}\right)$ indicate that the higher concentration of both polymers decreases the polydispersity index value, which is also illustrated by the 3D surface of polydispersity index (fig. 2C). This finding is in accordance with another study which finds that the increase of polymer concentrations promotes a decrease in polydispersity index value [23]. Nevertheless, the interaction between the concentration of $\mathrm{PC}$ and $\mathrm{CS}\left(\mathrm{X}_{1} \mathrm{X}_{3}\right)$ yielded a positive effect. This interaction lead to an increase of polydispersity index values due to the aggregations in the nanoparticle sample that occurs as the result of the increase of ionic interaction between the PC's carboxylate groups and CS's amino groups [24].
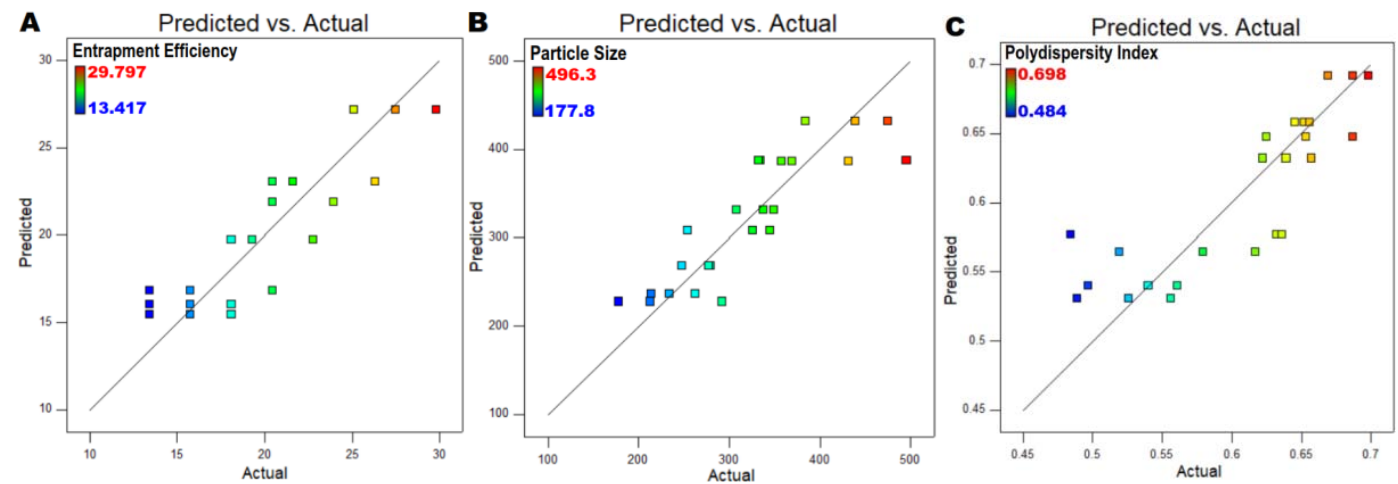

Fig. 1: Actual and predicted value correlation of entrapment efficiency (A), particle size (B), and polydispersity index (C) 

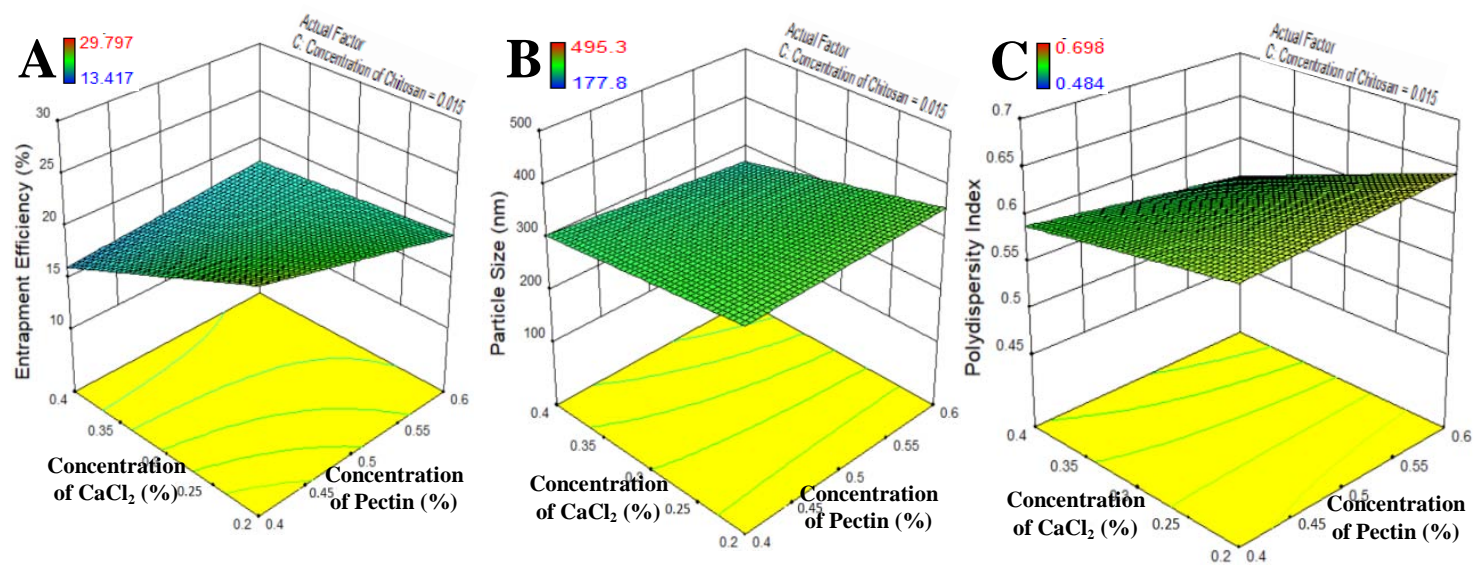

Fig. 2: Interaction of factors of $X_{1}, X_{2}$, and $X_{3}$ on entrapment efficiency (A), particle size (B), and polydispersity index (C) illustrated in the form of 3D surface diagrams

\section{The prediction and verification of the optimum condition of nanoparticle}

The selection of the optimum condition of nanoparticle preparation can be done by considering the desirability value of the solutions provided by the Design-Expert software. Desirability is an indicator that describes the closeness between the prediction of response values and the observed response values. The desirability is presented at the value between 0 and 1 , where the 0 value indicates an undesirable value and 1 indicates the desirable value or the ideal response. The desirability considered as good if it has the value close to 1 [25].

Based on the determination of goal and importance of each response, the highest desirability value of 0.839 was obtained and considered as the optimum condition of nanoparticle preparation with the concentration of $\mathrm{PC}\left(\mathrm{X}_{1}\right) 0.4 \%(\mathrm{w} / \mathrm{v})$, the concentration of $\mathrm{CC}\left(\mathrm{X}_{2}\right) 0.2 \%$ $(\mathrm{w} / \mathrm{v})$, and the concentration of chitosan $\left(\mathrm{X}_{3}\right) 0.01 \%(\mathrm{w} / \mathrm{v})$. The prediction values of each response were $27.162 \%$ for entrapment efficiency $\left(\mathrm{Y}_{1}\right), 267.8 \mathrm{~nm}$ for particle size $\left(\mathrm{Y}_{2}\right)$, and 0.692 for polydispersity index $\left(\mathrm{Y}_{3}\right)$. The contour plot of the desirability value of 0.839 can be seen in fig. 3 .

The results of the verification study of the three responses were provided in table 4 . The entrapment efficiency value of the verification study was $24.791 \pm 2.84 \%$, which was theoretically in the range of $95 \%$ CI verification range (24.765 to $29.559 \%)$ and $95 \%$ PI range (22.117 to $32.707 \%$ ). The result of the statistical test of entrapment efficiency using one-sample t-test showed that the p-value of the test was 0.285 $(>0.05)$, which indicated that the entrapment efficiency value of the verification study was not significantly different from the predicted value. The quite low entrapment efficiency value of $24.791 \pm 2.84 \%$ may be attributed to the physichochemical characteristic of the drug used in this study. TM is a hydrophilic drug that has a possibility to escape to the external environment that overwhelmed by hydrophilic substances. This phenomenon causes only a few interactions occurred between the drug and the polymers and lead to poor entrapment efficiency [26].

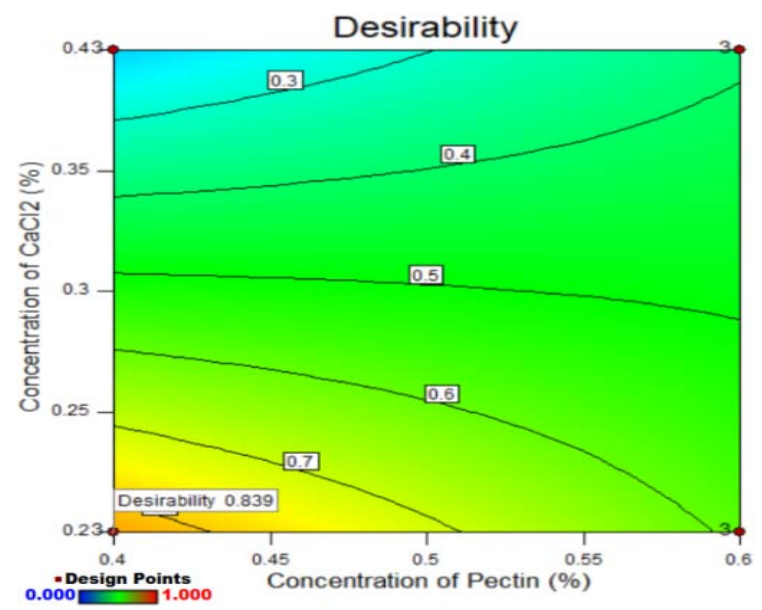

Fig. 3: Desirability value of optimal condition of nanoparticle preparation

Table 4: The prediction and observation value of optimum condition with the statistical range of verification

\begin{tabular}{|c|c|c|c|c|c|c|c|}
\hline \multirow[t]{2}{*}{ Response } & \multirow[t]{2}{*}{ Prediction } & \multirow[t]{2}{*}{ Observation* $^{*}$} & \multirow[t]{2}{*}{ One Sample t-test** } & \multicolumn{2}{|l|}{ 95\% CI } & \multicolumn{2}{|l|}{ 95\% PI } \\
\hline & & & & Low & High & Low & High \\
\hline 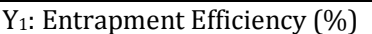 & 27.162 & $24.791 \pm 2.84$ & 0.285 & 24.765 & 29.559 & 22.117 & 32.207 \\
\hline $\mathrm{Y}_{2}$ : Particle Size $(\mathrm{nm})$ & 267.8 & $274.867 \pm 14.45$ & 0.486 & 218.013 & 317.587 & 168.227 & 367.373 \\
\hline $\mathrm{Y}_{3}$ : Polydispersity Index & 0.692 & $0.634 \pm 0.066$ & 0.269 & 0.653 & 0.730 & 0.610 & 0.772 \\
\hline
\end{tabular}

*results expressed in the mean of $\mathrm{n}=3 \pm$ standard deviation (SD), ** $(p>0.05)$

The result of verification study of particle size was also indicated that the values observed in the verification were not significantly different with the predicted values and in the range of $95 \% \mathrm{CI}$ and 95\% PI, while the polydispersity index verification study showed that the observed value was in the range of $95 \%$ PI. Based on the one-sample t-test results of the observed value of particle size and polydispersity index, the p-values of particle size and polydispersity index were respectively 0.486 and 0.269 , which indicated that the observed values were not significantly different from the predicted values.
The particle size of $274.867 \pm 14.45 \mathrm{~nm}$ is considered an acceptable size for the intended use of the nanoparticle. The TM nanoparticle is intended to be administrated on the skin surface as the therapy of infantile hemangioma. The maximal depth penetration of particle size in the range between 250 and $500 \mathrm{~nm}$ can only reach the stratum corneum and unable to penetrate deeper through the skin [27]. The polydispersity index value of $0.634 \pm 0.066$ (less than 0.7 ) indicates that the nanoparticle sample is able to be analyzed using dynamic light scattering method due to a narrow particle size distribution. The optimum formula possesses monodisperse particle 
distribution, which indicates size uniformity of the particles inside of the nanoparticle sample with small variation between individual particle $[28,29]$.

\section{CONCLUSION}

The optimization study to observe the optimum condition of TM nanoparticle preparation using ionic gelation technique was successfully applied using the method of $2^{3}$ factorial design. The optimum condition which produced good results of the response of entrapment efficiency, particle size, and polydispersity index was found with the concentration of PC, CC, and CS of $0.4 \%(\mathrm{w} / \mathrm{v}), 0.2 \%$ $(\mathrm{w} / \mathrm{v})$, and $0.01 \%(\mathrm{w} / \mathrm{v})$, respectively.

\section{ACKNOWLEDGMENT}

The authors would like to thank the research grant of Penelitian Dasar Unggulan Perguruan Tinggi (PDUPT) 2018 KemenristekdiktiUniversitas Gadjah Mada for funding this research.

\section{AUTHORS CONTRIBUTIONS}

All of the authors listed in the manuscript has contributed equally

\section{CONFLICT OF INTERESTS}

The authors declare there is no conflict of interest is associated with this work

\section{REFERENCES}

1. Danarti R, Ariwibowo L, Radiono S, Budiyanto A. Topical timolol maleate $0.5 \%$ for infantile hemangioma: its effectiveness compared to ultrapotent topical corticosteroids-a single-center experience of 278 cases. Dermatology (Basel) 2016;232:566-71.

2. Zheng JW, Zhang L, Zhou Q, Mai HM, Wang YA, Fan XD, et al. A practical guide to treatment of infantile hemangiomas of the head and neck. Int J Clin Exp Med 2013;6:851-60.

3. Frommelt P, Juern A, Siegel D, Holland K, Seefeldt M, Yu J, et al. Adverse events in young and preterm infants receiving topical timolol for infantile hemangioma. Pediatr Dermatol 2016; 33:405-14

4. Zhang Z, Tsai PC, Ramezanli T, Michniak Kohn BB. Polymeric nanoparticles-based topical delivery systems for the treatment of dermatological diseases. Wiley Interdiscip Rev: Nanomed Nanobiotechnol 2013;5:205-18.

5. Kunjachan S, Jose $S$, Lammers $T$. Understanding the mechanism of ionic gelation for the synthesis of chitosan nanoparticles using qualitative techniques. Asian J Pharm 2014;4:148-53.

6. Grabnar PA, Kristl J. The manufacturing techniques of drugloaded polymeric nanoparticles from preformed polymers. J Microencapsul 2011;28:323-35.

7. Nagpal K, Singh SK, Mishra DN. Chitosan nanoparticles: a promising system in novel drug delivery. Chem Pharm Bull 2010;58:1423-30.

8. Grabnar PA, Kristl J. Physicochemical characterization of protein-loaded pectin-chitosan nanoparticles prepared by polyelectrolyte complexation. Pharmazie 2010;65:851-2.

9. de Pinho Neves AL, Milioli CC, Müller L, Riella HG, Kuhnen NC, Stulzer HK. Factorial design as a tool in chitosan nanoparticles development by ionic gelation technique. Colloids Surf A 2014;445:34-9.

10. Ilka R, Mohseni M, Kianirad M, Naseripour M, Ashtari K, Mehravi B. Nanogel-based natural polymers as smart carriers for the controlled delivery of timolol maleate through the cornea for glaucoma. Int J Biol Macromol 2018;109:955-62.

11. Siafaka PI, Titopoulou A, Koukaras EN, Kostoglou M, Koutris E, Karavas E, et al. Chitosan derivatives as effective nanocarriers for ocular release of timolol drug. Int J Pharm 2015;495:249-64.

12. Shaw R, Festing MFW, Peers I, Furlong L. Use of factorial designs to optimize animal experiments and reduce animal use. ILAR J 2002;43:223-32.

13. Bhoskar M, Patil P. Development and evaluation of paclitaxel loaded nanoparticles using 24 factorial design. Int J Curr Pharm Res 2015;7:64-72.

14. Jain A, Jain SK. Formulation and optimization of temozolomide nanoparticles by 3 factors 2 level factorial design. Biomatter 2013;3:1-13.

15. Pham DT, Saelim N, Tiyaboonchai W. Design of experiments model for the optimization of silk fibroin based nanoparticle. Int J Appl Pharm 2018;10:195-201.

16. Shiyan $S$, Hertiani T, Martien R, Nugroho AK. Optimization of a novel kinetic-assisted infundation of white tea (Camellia sinensis) using central composite design. Int J Appl Pharm 2018;10:259-67.

17. Setyawan EI, Setyowati EP, Rohman A, Nugroho AK. Central composite design for optimizing the extraction of EGCG from green tea leaf (Camellia sinensis L.). Int J Appl Pharm 2018;10:211-6.

18. Pawar AP, Gadhe AR, Venkatachalam P, Sher P, Mahadik KR. Effect of core and surface cross-linking on the entrapment of metronidazole in pectin beads. Acta Pharm 2008;58:78-85.

19. Sharma R, Ahuja M, Kaur H. Thiolated pectin nanoparticles: preparation, characterization and ex vivo corneal permeation study. Carbohydr Polym 2012;87:1606-10.

20. Opanasopit $\mathrm{P}$, Apirakaramwong A, Ngawhirunpat $\mathrm{T}$, Rojanarata T, Ruktanonchai U. Development and characterization of pectinate micro/nanoparticles for gene delivery. AAPS PharmSciTech 2008;9:67-74.

21. Zaki SSO, Ibrahim MN, Katas H. Particle size affects concentration-dependent cytotoxicity of chitosan nanoparticles towards mouse hematopoietic stem cells. J Nanotechnol 2015. http://dx.doi.org/10.1155/2015/919658

22. Maciel VBV, Yoshida CMP, Pereira SMSS, Goycoolea FM, Franco TT. Electrostatic self-assembled chitosan-pectin nano-and microparticles for insulin delivery. Molecules 2017;22:1-21.

23. Melo NFS, Campos EVR, Paula ED, Rosa AH, Fraceto LF. Factorial design and characterization studies for articaine hydrochloride loaded alginate/chitosan nanoparticles. J Colloid Sci Biotechnol 2013;2:146-52.

24. Masarudin MJ, Cutts SM, Evison BJ, Phillips DR, Pigram PJ. Factors determining the stability, size distribution, and cellular accumulation of small, monodisperse chitosan nanoparticles as candidate vectors for anticancer drug delivery: application to the passive encapsulation of ${ }^{14} \mathrm{C}$-doxorubicin. Nanotechnol Sci Appl 2015;8:67-80.

25. Candioti LV, De Zan MM, Camara MS, Goicoechea HC. Experimental design and multiple response optimization. Using the desirability function in analytical methods development. Talanta 2014;124:123-38.

26. Abdalla KA, Kamoun EA, Maghraby GME. Optimization of the entrapment efficiency and release of ambroxol hydrochloride alginate beads. J Appl Pharm Sci 2015;5:13-9.

27. Poland CA, Read SAK, Varet J, Carse G, Christensen FM, Hankin SM. Dermal absorption of nanomaterials part of the "Better control of nano" initiative 2012-2015. Denmark: The Danish Environmental Protection Agency; 2013.

28. Danaei M, Dehghankhold M, Ataei S, Hasanzadeh Davarani F, Javanmard R, Dokhani A, et al. Impact of particle size and polydispersity index on the clinical applications of lipidic nanocarrier systems. Pharmaceutics 2018;10:57.

29. Zayed GM, El-feky GS. Growth factor loaded functionalized gold nanoparticles as a potential targeted treatment for acute renal failure. Int J Appl Pharm 2019;11:174-85. 